\title{
Residência multiprofissional em saúde: percepções de residentes, preceptores e tutores
}

\section{Multiprofessional residence in health: perceptions of residents, preceptors and tutors Residencia multiprofesional en salud: percepciones de residentes, preceptores y tutores}

\author{
Recebido: 31/08/2017 \\ Aprovado: $31 / 07 / 2018$ \\ Publicado: 13/05/2019
}

\author{
Diane Coelho Pereira ${ }^{1}$ \\ Karina Piccin Zanni ${ }^{2}$ \\ José Henrique da Silva Cunha ${ }^{3}$
}

O presente estudo teve como objetivo descrever a percepção dos tutores, preceptores e residentes sobre a experiência vivenciada no programa de Residência Integrada Multiprofissional em Saúde da Universidade Federal do Triângulo Mineiro (RIMS-UFTM), no que se refere à formação e qualificação profissional. Tratase de uma pesquisa descritiva e exploratória com abordagem qualitativa, realizada em 2015. Os dados foram coletados por meio de entrevista semiestruturada e interpretados seguindo a análise de conteúdo temática. Emergiram as categorias: "Interesses e motivações pela RIMS - UFTM"; "Ações desenvolvidas pelos residentes, preceptores e tutores"; "A RIMS-UFTM como cenário de prática do trabalho em equipe" e "Sugestões para melhorias do programa". Verificou-se que as experiências vivenciadas nesse programa foram vistas como uma oportunidade para ampliar o conhecimento teórico-prático profissional, acrescer o contato e aprendizado com os profissionais de diversas categorias e colaborar para mudanças no modelo de atendimento aos usuários do Sistema Único de Saúde.

Descritores: Avaliação de programas e projetos de saúde; Capacitação de recursos humanos em saúde; Equipe de assistência ao paciente; Internato não médico.

This study aimed to describe the perception of the residents, preceptors and tutors about the experience lived in the program of Multiprofessional Integrated Residency in Health of the Federal University of Triângulo Mineiro (RIMS-UFTM), Brazil, with regard to training and professional qualification. This is a descriptive and exploratory research with qualitative approach, carried out in 2015. Data were collected using semi-structured interviews and interpreted following the thematic content analysis. The following categories emerged: "Interests and motivations for RIMS - UFTM "; "Actions taken by the residents, preceptors and tutors"; " RIMS-UFTM as practice setting of the team work" and "Suggestions for program improvement." It was found that the experiences lived in this program were seen as an opportunity to expand the theoretical and practical professional knowledge, add contact and learning with professionals of various categories and contribute to changes in the service to users of the Unified Health System.

Descriptors: Program evaluation; Health human resource training; Patient care team; Internship, Nonmedical.

El presente estudio tuvo como objetivo describir la percepción de los tutores, preceptores y residentes sobre la experiencia vivenciada en el programa de Residencia Integrada Multiprofesional en Salud de la Universidad Federal do Triângulo Mineiro (RIMS-UFTM), Brasil en lo que se refiere a la formación y calificación profesional. Tratase de una investigación descriptiva y exploratoria con abordaje cualitativa, realizada en 2015. Los datos fueron colectados por medio de encuestas semiestructuradas e interpretados siguiendo el análisis de contenido temática. Emergieron las categorías: "Intereses y motivaciones por la RIMS-UFTM"; "Acciones desarrolladas por los residentes, preceptores y tutores"; "La RIMS-UFTM como escenario de práctica del trabajo en equipo" y "Sugerencias para mejorías del programa". Se ha verificado que las experiencias vivenciadas en ese programa fueron vistas como una oportunidad para ampliar el conocimiento teórico-práctico profesional, acrecer el contacto y aprendizaje con los profesionales de diversas categorías y colaborar para cambiar en el modelo de atendimiento a los usuarios del Sistema Único de Salud.

Descriptores: Evaluación de programas y proyectos de salud; Capacitación de recursos humanos en salud; Grupo de atención al paciente; Internado no médico.

1. Terapeuta Ocupacional. Acupunturista. Especialista em Saúde da Criança e do Adolescente, Uberaba, MG, Brasil. ORCID: 0000-0003-4440-5942 E-mail: dianecoelho4@gmail.com

2. Terapeuta Ocupacional. Mestre em Educação Especial. Doutora em Neurociências. Professora Adjunta do Departamento de Terapia Ocupacional e Coordenadora da Área de Saúde da Criança e do Adolescente da Residência Multiprofissional em Saúde da Universidade Federal do Triângulo Mineiro, Uberaba, MG, Brasil. ORCID: 0000-0002-8456-5038 E-mail: kpzanni@hotmail.com

3. Terapeuta Ocupacional. Acupunturista. Especialista em Saúde do Adulto. Mestre em Atenção à Saúde. Uberaba, MG, Brasil. ORCID: 0000-0002-4255-6125 E-mail: josehenrique_dasilvacunha@hotmail.com 


\section{INTRODUÇÃO}

A s Residências Multiprofissionais em área profissional da saúde foram criadas pela lei $n^{\circ} 11.129$ de 2005¹, orientadas pelos princípios e diretrizes do Sistema Único de Saúde (SUS).

A Residência Multiprofissional em Saúde (RMS) é definida como modalidade de ensino de pós-graduação lato sensu, desenvolvida em regime de dedicação exclusiva e realizada sob supervisão docenteassistencial de responsabilidade conjunta dos setores da saúde e da educação. Abrange as profissões da área da saúde como educação física, biomedicina, ciências biológicas, enfermagem, farmácia, fonoaudiologia, fisioterapia, medicina veterinária, nutrição, psicologia, odontologia, serviço social e terapia ocupacional ${ }^{2}$.

O programa de RMS foi criado como estratégia para políticas de educação permanente que visa favorecer a produção das condições necessárias para mudanças no modelo tecnoassistencial, ainda hegemônico, de atenção em saúde no Brasil ${ }^{3}$. Neste sentido, esse programa deve proporcionar mudanças a partir da atuação multiprofissional, com vistas a favorecer a inserção qualificada dos jovens profissionais da saúde, no mercado de trabalho ${ }^{2}$.

Considera-se a RMS como um processo ainda em construção, com muitos caminhos a serem percorridos. Sob este aspecto, são citados, a necessidade de priorização do tempo para planejamento das ações e suporte pedagógico; amplo incentivo à participação e envolvimento dos residentes; necessidade de aprofundamento e fundamentação para assumir as aulas teóricas por parte dos preceptores; elaboração de instrumentos para avaliar o processo de aprendizagem coerentes com a estratégia pedagógica e garantia de tempo reservado do tutor para realização da tutoria e acompanhamento sistemático da equipe de residentes ${ }^{4}$.

Considerando o cenário atual da saúde pública no Brasil com grandes disparidades locais e regionais, especialmente no que se refere à formação profissional, à política de contratação/capacitação/formação de pessoal e ao acesso a processos de educação permanente $^{5}$ faz-se necessário pesquisas voltadas à caracterização dos programas de RMS sob a perspectiva de diferentes atores que as compõem.

Além disso, estudos ${ }^{6,7}$ apontam que o objeto de formação para a prática colaborativa nos programas de Residência Multiprofissional em Saúde, que se dá por meio da educação interprofissional, permite a aprendizagem compartilhada através da interação de diferentes áreas. Ressaltam ainda que essa temática ainda é pouco estudada, o que faz necessário o desenvolvimento de estudos.

A presente pesquisa teve como objetivo descrever a percepção dos tutores, preceptores e residentes sobre a experiência vivenciada no Programa da Residência Integrada Multiprofissional em Saúde da Universidade Federal do Triângulo Mineiro no que se refere à formação e qualificação profissional.

\section{MÉTODO}

O presente estudo caracterizou-se como um estudo descritivo e exploratório, de abordagem qualitativa.

A pesquisa foi realizada com tutores, preceptores e residentes da RIMS-UFTM, que atuaram no ano de 2014 no Hospital de Clínicas da Universidade Federal do Triângulo Mineiro (HC-UFTM) ou na Atenção Primária em Saúde (APS) do município de Uberaba Minas Gerais.

Este programa foi criado em 2010 e atualmente é composto por três áreas de concentração: saúde da criança e do adolescente; saúde do adulto e, saúde do idoso, envolvendo profissionais de educação física, biomedicina, enfermagem, fisioterapia, nutrição, psicologia, serviço social e terapia ocupacional.

O HC-UFTM atende 27 municípios que compõem a macrorregião Triângulo Sul de Minas Gerais, sendo o único hospital público que oferece atendimento de alta complexidade distribuindo-se em estruturas operacionais como: internação hospitalar, ambulatorial, pronto-socorro e serviços de diagnóstico e tratamentos especializados. 
Os setores de atuação dos residentes, preceptores e tutores são Enfermaria Pediátrica, Unidade de Terapia Intensiva Neonatal, Ambulatório de Pediatria, Hospital Dia, Clínica Médica, Pronto Socorro, Oncologia/ Hematologia, Ambulatório Maria da Glória e Laboratório de Análises Clínicas.

Na APS, os locais de atuação ocorrem em instituições distribuídas em Distritos Sanitários. Caracterizam-se como instituições públicas e seguem as orientações descritas na Política Nacional de Atenção Básica (PNAB) tendo como finalidade desenvolver ações com o mais alto grau de capilaridade e descentralização, estando no local mais próximo da vida dos indivíduos. Deve ser a principal porta de entrada do sistema de saúde, ser o contato preferencial dos usuários e o centro de comunicação com toda a rede de atenção à Saúde ${ }^{6}$.

A seleção dos participantes da pesquisa seguiu os critérios de inclusão: tutores, preceptores e residentes que atuaram no programa no ano de 2014 no contexto hospitalar ou na APS; e, três representantes de cada área de concentração sendo eles, tutor, preceptor e residente. A amostra foi intencional e se deu por saturação, consistindo, portanto, na suspensão de novos participantes quando os dados das entrevistas passaram a apresentar redundância ou repetição, não sendo relevante persistir na coleta ${ }^{8}$.

A coleta de dados ocorreu no período de outubro a novembro de 2015 e, foi utilizado um roteiro de entrevista semiestruturado que foi construído no programa do Microsoft Word versão 2010.

Este roteiro continha doze questões relacionadas às ações desenvolvidas pelos participantes da pesquisa no programa da RIMS-UFTM: 1. Quais são as ações desenvolvidas no seu cotidiano no programa de RIMS-UFTM? 2. Qual a sua percepção em relação às seguintes atividades (atividades teóricas; atividades práticas; atividades teórico-práticas)? 3. Qual a sua opinião em relação à estrutura física e materiais/recursos que a RIMS-UFTM disponibiliza para o desenvolvimento das ações? 4. Qual a sua opinião em relação à carga horária que você dedica às atividades da RIMS-UFTM? 5. Na sua percepção, o sistema de remuneração dos residentes é adequado? 6. Em relação aos tutores e preceptores você acredita que os mesmos deveriam receber remuneração pelo trabalho que desenvolvem na RIMS-UFTM? 7. Com quais profissionais você se relaciona durante suas práticas como residente, tutor ou preceptor? 8. Ocorrem reuniões, orientações, tutorias, supervisões e/ou outras atividades, dentre as várias atividades que devem ser realizadas? Em caso afirmativo, na sua perspectiva, como são feitas essas atividades e se elas atendem aos objetivos e demandas da RIMS-UFTM? 9. Pensando na área de concentração em que você atua, como você classificaria o trabalho multiprofissional que é desenvolvido? Por quê? 10. Como você descreve a relação tutor/preceptor/residente a partir de suas experiências na RIMS-UFTM? 11. Quais são suas sugestões para melhorias para o programa da RIMS-UFTM? 12 . 0 que o motiva a estar na RIMS-UFTM, e as vivências na RIMS-UFTM acrescentaram algo para o seu crescimento pessoal?

A coleta de dados se deu após contato pessoal com os potenciais participantes, na qual se explicou aos mesmos sobre o objetivo do estudo, a metodologia que seria utilizada, a garantia de não serem identificados e do sigilo das informações, e a liberdade de se recusarem ou sair a qualquer tempo desse estudo. Frente o aceite e assinatura do Termo de Consentimento Livre e Esclarecido (TCLE), as perguntas foram encaminhadas por meio de correio eletrônico aos participantes.

0 material resultante das respostas foi analisado por meio da técnica de análise de conteúdo temática, seguindo as fases de préanálise; exploração do material; tratamento e interpretação dos resultados obtidos ${ }^{9}$.

Na pré-análise foi realizada uma leitura flutuante do material com vistas a uma impregnação do conteúdo. Na exploração do material, os temas foram sendo agrupados conforme seus conteúdos, a partir das unidades de significado, até se obter a formação de categorias. Já no tratamento e interpretação dos resultados embasou-se nos referenciais teóricos utilizados, o qual subsidiou a formação das categorias. 
Para garantir o anonimato dos participantes, foram utilizadas letras para representar as funções dos mesmos na RIMSUFTM: R (residente), P (preceptor), T (tutor), seguidas do número sequencial das entrevistas.

Essa pesquisa foi aprovada pelo Comitê de Ética em Pesquisa da Universidade Federal do Triângulo Mineiro (CEP/UFTM) de acordo com o parecer $\mathrm{n}^{-} \mathbf{0} 1.278 .408$ de 2015, respeitando os preceitos éticos da Resolução 466/12 do Conselho Nacional de Saúde.

\section{RESULTADOS}

Participaram do estudo nove profissionais, sendo os residentes denominados $\mathrm{R} 1, \mathrm{R} 2$ e R3 pertencendo às categorias profissionais de psicologia, fisioterapia e terapia ocupacional, respectivamente, desenvolvendo todos suas atividades na APS no ano de 2015.

Os preceptores nomeados P1, P2 e P3 desempenharam suas ações no HC-UFTM contemplando as profissões de biomedicina, terapia ocupacional e fisioterapia. Os tutores foram nomeados $\mathrm{T} 1$, $\mathrm{T} 2 \mathrm{e} \mathrm{T} 3$, sendo que $\mathrm{T} 1 \mathrm{era}$ assistente social e atuava na APS, enquanto T2 e T3 eram enfermeiros e atuavam respectivamente na APS e no HC - UFTM (Quadro 01).

Quadro 1. Pesquisandos por função, profissão e local de atuação. Uberaba (MG), 2015.

\begin{tabular}{|c|c|c|c|}
\hline Participantes & Função & Profissão & Local de Atuação \\
\hline R1 & Residente & Psicologia & $\begin{array}{c}\text { Unidade Matricial de Saúde } \\
\text { (UMS) }\end{array}$ \\
\hline R2 & Residente & Fisioterapia & $\begin{array}{c}\text { Unidade Básica de Saúde } \\
\text { (UBS) }\end{array}$ \\
\hline R3 & Residente & Terapia Ocupacional & UMS \\
\hline P1 & Preceptor & Biomedicina & HC - UFTM \\
\hline P2 & Preceptor & Terapia Ocupacional & HC - UFTM \\
\hline P3 & Preceptor & Fisioterapia & UMS \\
\hline T1 & Tutor & Serviço Social & UBS \\
\hline T2 & Tutor & Enfermagem & HC - UFTM \\
\hline T3 & Tutor & Enfermagem & \\
\hline
\end{tabular}

A partir da análise dos dados emergiram quatro categorias: Interesses e motivações pela RIMS - UFTM; Ações desenvolvidas pelos residentes, preceptores e tutores; A RIMS-UFTM como cenário de prática do trabalho em equipe e Sugestões para melhorias do programa. Tais categorias serão apresentadas a seguir:

\section{Interesses e motivações pela RIMS - UFTM}

Os participantes da entrevista foram questionados em relação aos interesses e motivações ao entrar e estar no programa. Nesta categoria, as reflexões dos residentes permearam questões relacionadas à qualificação profissional, oferta de um trabalho de qualidade para os usuários do SUS, busca do entendimento sobre as diversas formas de se entender o ser humano a partir da visão de diversas profissões e o sistema de remuneração, como mostram as falas abaixo: Qualificação profissional para atuar no âmbito do SUS; adquirir experiência prática e contribuir com minha equipe para oferecer um trabalho de qualidade para os usuários que atendemos (R3).

O aprendizado sobre as diferentes formas de se entender o ser humano, a partir de pontos de vistas de diferentes profissões, a relação desenvolvida com minhas colegas de trabalho e o valor da bolsa (R1).

Os preceptores citaram a possibilidade de atuar de forma multidisciplinar, colaborando com conhecimento teóricoprático dos residentes e troca de conhecimento entre profissionais, conforme referem os participantes:

o que me motivou a entrar na RIMS foi a possibilidade de atuar de forma multidisciplinar, bem como poder colaborar com meus conhecimentos (P1).

Gosto da troca de conhecimento técnico e do desafio de relacionar minha prática em busca de uma excelência e atualização (P2).

Os tutores mencionaram a contribuição com reflexões críticas acerca do papel da RMS e sobre as mudanças nas políticas de saúde necessárias no contexto atual, além da importância da atuação e impacto que gera o 
atendimento multiprofissional com vistas a integralidade, como apontam as afirmativas:

A nossa participação na RIMS é atravessada por uma série de questões que evidenciam as contradições das políticas de saúde (inclusive políticas de formação de trabalhadores da saúde), bem como do próprio sistema capitalista, e do seu ideário neoliberal. 0 contato com essas contradições, em alguma medida, nos faz querer participar desse processo de forma a contribuir com reflexões críticas acerca do papel que a RMS e as políticas de saúde vem assumindo no contexto atual. Precisamos contar com sujeitos que questionam esse modelo de formação que está sendo desenvolvido e evidenciam as contradições que estão colocados no âmbito das políticas de saúde (T1).

A proposta de atuação e o impacto que gera um atendimento multidisciplinar, por acreditar que necessitamos de um atendimento integral e em equipe (T2).

\section{Ações desenvolvidas pelos residentes, preceptores e tutores}

Os residentes entrevistados, ao serem questionados sobre as ações que desenvolviam no cotidiano da RIMS-UFTM informaram que desempenhavam atividades práticas, teóricas e teórico-práticas nas áreas de concentração em saúde da criança e do adolescente (R1), do adulto (R3) ou do idoso (R2), distribuídas em 60 horas semanais.

Sabe-se que na carga horária prática dos residentes, as ações são voltadas para assistência, incluindo atendimentos ambulatoriais específicos realizados por diversas categorias profissionais; atendimentos ambulatoriais multiprofissionais realizados pelas equipes de residentes de cada área de concentração; atendimentos grupais; visitas domiciliares; educação permanente junto às equipes de Estratégia de Saúde da Família da UMS de referência e atividades de plantão, envolvendo ações na comunidade da área de abrangência das UMS ou UBS em que os residentes atuam.

As atividades teóricas estão relacionadas à elaboração do Trabalho de Conclusão de Curso (TCC) e participação em aulas distribuídas no eixo transversal, destinadas a todos os residentes matriculados no programa; eixo de concentração, atribuído aos residentes das áreas de concentração em saúde da criança e do adolescente, do adulto e do idoso; e eixo específico remetido especificamente às diversas categorias profissionais que compõe o programa em questão.

Em relação às atividades teóricopráticas, os residentes informaram que são cumpridas através de participação em reuniões com tutores e preceptores, envolvendo estudos de casos e orientações específicas, sendo realizadas entre as equipes de cada área de concentração e nas próprias categorias profissionais.

Neste sentido os residentes relataram suas percepções em relação às ações realizadas no programa, afirmando:

Creio que as atividades práticas têm suas deficiências, mas vejo mais como desafios, por se tratar do serviço público que está em constante evolução (R2).

As atividades teóricas (...) são atividades que colaboram com nossa formação, mas ainda tem algumas falhas, entre elas falta de professor às vezes para dar aula e de materiais para colaborar para o enriquecimento das mesmas. Dentre esses aspectos, acho que a RIMS ainda é nova, mas está no caminho certo para promover uma formação rica para os futuros profissionais que irão atuar do âmbito do SUS (R3).

Algumas atividades teórico-práticas possuem qualidade, eficiência e conteúdo, enquanto outras estão bem deficitárias, dependendo do envolvimento do tutor e do preceptor (quando há) com as atividades da residência (R1).

Os preceptores entrevistados relataram que desenvolviam suas ações de forma prática e teórico-prática. As atividades práticas eram desenvolvidas no HC-UFTM juntamente com os residentes de sua própria categoria profissional e apenas o preceptor (P2), informou que desenvolvia preceptoria junto à equipe de residentes da área de concentração em saúde da criança e do adolescente. Já as atividades teórico-práticas eram desempenhadas por meio de estudos de casos e orientações específicas para o residente de sua própria categoria profissional. 0 preceptor (P1) informou que além dessas ações também ministrava aulas no eixo específico. Em relação a este eixo P3 afirmou: É necessário estudar mais, valorizar e conhecer outras abordagens teóricas, ser mais criativa, dinâmica $e$ tolerante e ainda conviver com profissionais que querem contribuir na construção de atendimentos mais humanizados e eficazes (P3).

Os residentes entrevistados informaram que não eram orientados por preceptores nos cenários de prática das UMS e UBS devido à quantidade reduzida de profissionais que atuavam nas unidades de saúde ou ausência 
de algumas categorias profissionais, além de pouca disponibilidade por parte da equipe local em desenvolver atividades de preceptoria.

Os tutores participantes da entrevista declararam que desempenhavam ações voltadas a orientações teórico-práticas, individuais ou grupais, direcionadas aos residentes de sua própria categoria profissional e a área de concentração a qual fazia parte. Também relataram que orientavam TCC, ministravam aulas nos eixos específicos e de concentração além de fazerem parte da coordenação nas áreas de concentração. Abaixo segue relato de T1 sobre sua percepção em relação às ações dos tutores:

De uma forma geral penso que as atividades, como as reuniões, orientações e tutorias cumprem os objetivos propostos, mas claro que esse processo é atravessado por uma série de questões que fragilizam e afetam negativamente a RIMS (T1).

\section{A RIMS-UFTM como cenário de prática do trabalho em equipe}

Os residentes, preceptores e tutores ao serem questionados sobre o trabalho em equipe desenvolvido na área de concentração da qual faziam parte, relataram que este era desempenhado de forma multidisciplinar e/ou interdisciplinar. 0 trabalho em equipe multidisciplinar foi citado nos momentos em que eram realizados atendimentos individuais ou grupais por diferentes categoriais profissionais, cada uma delas atuando em sua especificidade, como aponta R2:

São realizados individualmente por cada categoria profissional de acordo com a necessidade e demanda (R2).

Já o trabalho em equipe interdisciplinar foi mencionado quando se realizavam reuniões em equipe, discussões de casos clínicos, planejamento e execuções de planos terapêuticos de forma coletiva, envolvendo mais de uma categoria profissional, como mostra a fala abaixo:

Estamos conseguindo atuar dessa forma, discutimos os casos dos pacientes e traçamos um plano terapêutico singular para os pacientes que atendemos (R3).

Os participantes da entrevista apontaram como obstáculos para a realização do trabalho multiprofissional e a dificuldade de engajamento de todos os integrantes da equipe, 0 entendimento sobre as especificidades e focos de atuação de cada categoria profissional e dificuldades em realizar reuniões em equipes constantemente. No entanto, reconheceram a importância do desenvolvimento do trabalho em equipe para o próprio crescimento profissional e para o atendimento integral das necessidades e demandas dos pacientes atendidos.

\section{Sugestões para melhorias do programa}

Os participantes do estudo apontaram aspectos muito semelhantes em relação a essa categoria. Por meio das experiências vivenciadas ao longo da permanência no programa, os entrevistados relataram aquisição de crescimento pessoal e profissional, sendo este um espaço rico em aprendizado.

Embora tenham trazido aspectos positivos, os participantes apontaram sugestões para melhorias da RIMS - UFTM, como, discutir e atualizar o Plano Político Pedagógico (PPP) de acordo com as demandas atuais; necessidade de maior adesão e engajamento dos atores que compõem o programa, principalmente tutores e preceptores; realização de encontros sistemáticos e capacitação dos tutores e preceptores com seus residentes, no sentido de promover a aproximação e troca de experiências; remuneração ou contabilização das horas dedicadas ao programa na carga horária de trabalho dos tutores e preceptores; redução da carga horária do residente com vistas ao atendimento de qualidade e redução da precarização do trabalho; verificar o método e conteúdo das aulas ministradas, principalmente do eixo transversal; fortalecimento das parcerias entre UFTM, HCUFTM e Secretária de Saúde; aproximação dos residentes com equipes de trabalho nos cenários de atuação; e elaboração/divulgação de pesquisas voltadas ao trabalho multidisciplinar e interdisciplinar desenvolvidos no âmbito da residência.

\section{DISCUSSÃO}

$\mathrm{Na}$ categoria "Interesses e motivações pela RIMS-UFTM", a motivação para um trabalho tem íntima relação com a satisfação que ele proporciona, em como foi escolhido e com o 
significado que cada um atribui à atividade que realiza ${ }^{10}$. Trabalha-se para dar significado a própria vida e à sociedade em que se vive, pela necessidade em se contribuir para a organização de seu próprio trabalho, especialmente na superação das incoerências entre a organização prescrita e a real ${ }^{11}$.

Os apontamentos apresentados pelos residentes nessa referida categoria, corroboram com um estudo que objetivou compreender os significados das experiências de formação dos pós-graduandos do programa de RMS vinculado a uma instituição federal de ensino, na qual os participantes relataram que a residência possibilitou obter novos conhecimentos acerca de outras áreas e permitiu atender o paciente de forma integral através do trabalho multiprofissional ${ }^{12}$.

No que concerne aos interesses e motivações expostos pelos preceptores, o resultado de um estudo indica que após analisar as experiências de preceptores da RMS na área da fisioterapia, aponta-se que para uma nova proposta de cuidado e ensino, os residentes despertam nos preceptores o desejo e a necessidade de se atualizarem e buscarem constantemente construir seu currículo embasado na prática multiprofissional e humanizada, consolidada em subsídios teóricos ${ }^{13}$.

Levando em consideração as respostas mencionadas pelos tutores nesse eixo, observa-se que existe a necessidade de se produzir mudanças no modelo de atenção à saúde, sendo considerada uma emergência social. Neste sentido, o governo passou a debater e criar estratégias para a implementação de políticas na tentativa de instituir uma nova organização dos serviços que possam dar conta das necessidades dos indivíduos. Nesta perspectiva, o programa de RMS foi apresentado como estratégia para reorganização da Atenção Básica que objetivou produzir as condições necessárias para a mudança no modelo médicoassistencial restritivo de atenção em saúde 3 .

Pela categoria "Ações desenvolvidas pelos residentes, preceptores e tutores", pode-se dizer que as ações desenvolvidas, estão de acordo com o disposto na Resolução da Comissão Nacional de Residência
Multiprofissional em Saúde (CNRMS), sendo necessário que as RMS contemplem atividades práticas, teóricas e teórico-práticas organizadas em um eixo transversal comum, a todas as profissões envolvidas, um ou mais eixo(s) para as áreas de concentração, além de eixo relacionado aos núcleos de saberes de cada profissão ${ }^{2}$.

De acordo com as falas apresentadas pelos residentes, um estudo ${ }^{14}$ traz que a formação lato sensu dos programas de residência em saúde, fundamenta-se na educação pelo trabalho e o processo concretiza-se no serviço através da articulação envolvendo teoria e prática. Aponta também que o envolvimento entre residentes, preceptores e tutores se faz necessário devido à importância do compartilhamento do ensinar e aprender, a partir de reflexões sobre a prática, da troca de experiências e re(construção) do conhecimento nos cenários da atenção à saúde.

0 preceptor é o profissional que participa da formação do residente com vistas a articular a prática ao conhecimento científico. É necessário domínio da prática clínica assim como os aspectos pedagógicos para transformar o cenário profissional em ambiente escolar ${ }^{15}$. Essa informação pode ser evidenciada em um estudo onde foi possível constatar que para acontecer a prática descrita acima, requererá do preceptor, a competência de mediar o processo de aprender-ensinar nos cenários de prática, problematizar a realidade e provocar um processo de reflexão e ação para (re) construção da prática clínica do residente ${ }^{14}$.

0 preceptor precisa ser protagonista, em razão do compartilhamento da responsabilidade na formação dos residentes. Neste contexto, a fundamentação pedagógica e científica oferecida pelos preceptores são imprescindíveis para que os residentes possam aplicar seus saberes nos cenários de prática, modificando-se assim o ambiente do cuidado em um espaço de múltiplas aprendizagens.

No que diz respeito à função de tutor, as atividades destinam-se a orientação acadêmica de preceptores e residentes, 
estruturadas preferencialmente nas modalidades de tutoria de núcleo e tutoria de campo $^{2}$. Ambas são orientações voltadas à discussão das atividades teóricas, práticas e teórico-práticas, porém a tutoria de núcleo destina-se ao núcleo específico profissional e a tutoria de campo contempla os núcleos de saberes e práticas das diferentes profissões que compõem a área de concentração do programa.

Estas orientações deverão ocorrer através de encontros periódicos semanais com intuito de planejar e implementar ações voltadas à qualificação dos serviços e de novas tecnologias para atenção e gestão em saúde. É importante destacar que nas entrevistas realizadas com os preceptores nenhum participante informou que é orientado por tutores na execução de suas atividades. Conforme aponta um estudo ${ }^{16}$ o tutor deverá exercer atividades, que promovam o diálogo da equipe que inicialmente se encontra desarticulada visando integrar os diferentes saberes na perspectiva de sistematizar o processo de trabalho multiprofissional buscando produzir um fazer verdadeiramente interdisciplinar e transdisciplinar.

0 tutor ainda deverá organizar o processo de trabalho da equipe a partir da observação das condições de vida e saúde da população atendida, promover a comunicação horizontal entre os integrantes da equipe e destes com os membros da rede de apoio presentes no território, além de avaliação dos processos de formação com foco nos aspectos relacionais, nas ações interdisciplinares, na responsabilização sanitária da equipe e o aprofundamento teórico-conceitual de temas relacionados ao campo da saúde ${ }^{16}$.

$\mathrm{Na}$ categoria "A RIMS-UFTM como cenário de prática do trabalho em equipe", os residentes, preceptores e tutores relataram que este é desempenhado de forma multidisciplinar e/ou interdisciplinar, o que corrobora com o disposto na resolução CNRMS nํㅡ 2, de 13 de abril de 2012², que se descreve que as RMS devem adotar metodologias e dispositivos de gestão da clínica ampliada com vistas a garantir a formação fundamentada na atenção integral, multiprofissional e interdisciplinar.
Essas informações vão ao encontro dos resultados de uma pesquisa ${ }^{17}$, que mostrou a prática multiprofissional descrita pelas diferenças das profissões, evidenciando-se deste aspecto para agregar conhecimento de cada área. Outro estudo também demonstra que o trabalho em equipe multiprofissional está relacionado a objetivos comuns, compromisso compartilhado, identidade de equipe compartilhada, integração dos métodos de trabalho, funções e responsabilidades da equipe claras e interdependência entre os membros da equipe ${ }^{18}$.

O programa de RMS é compreendido assim, como uma oportunidade significativa de contato e aprendizado com profissionais de diversas categorias, possibilitando aos residentes assumirem uma nova atuação na prática profissional, pela qual a assistência aos usuários seja mais humanizada e abrangente, a partir de um compartilhamento efetivo dos conhecimentos de cada área ${ }^{18}$.

O coletivo se mostra importante, pois é na atuação multiprofissional e interdisciplinar que ocorre a apreensão dos vastos conhecimentos e práticas, pela qual as ações se convergem e possibilitam o trabalho em equipe. Nessa direção as ações integrais na saúde presumem a participação ativa dos seus membros e a conjunção dos conhecimentos de cada área do saber, na execução de projetos conjuntos que visem melhorar o nível de saúde das pessoas ${ }^{19}$.

Ao considerar a categoria "Sugestões para melhorias do programa", os participantes sugeriram ações necessárias para melhorias do mesmo. Algumas das colocações realizadas pelos participantes, vão ao encontro às discussões presentes em relatórios importantes, envolvendo avaliações que expressaram desafios, limites e contradições das RMS ${ }^{20,21}$. Destaca-se a manutenção do financiamento, avaliação dos programas, garantia de docentes para parte teórica e preceptoria nos serviços, ausência de diretrizes gerais para a formação, modelos de formação heterogêneos e implementação de dispositivos visando a (re) organização permanente das práticas de educação e da 
saúde revendo programas pontuais $\mathrm{e}$ fragmentados.

O programa de RMS faz parte de um importante movimento político para a garantia dos preceitos do SUS, sendo que, para sua consolidação é necessário se requerer e ganhar espaço nos cenários de discussões políticas e pedagógicas com vistas a sua legitimação. Pode-se dizer que as RMS constituem um projeto em construção que carece de ações e mudanças para se concretizar na prática e no cotidiano dos serviços ${ }^{22,23}$.

\section{CONCLUSÃO}

Os dados obtidos neste estudo revelaram sob a ótica de residentes, preceptores e tutores que o programa da RIMS-UFTM é compreendido pelos mesmos como uma oportunidade para ampliar o conhecimento teórico-prático profissional; acrescer o contato e aprendizado com os profissionais de diversas categorias; colaborar para mudanças no modelo de atendimento aos usuários do SUS com foco no trabalho multidisciplinar e interdisciplinar e, refletir sobre o papel da RMS e as transformações nas políticas de saúde, necessárias ao contexto atual.

Com base nas experiências vivenciadas ao longo da permanência no programa, os participantes da pesquisa apontaram reflexões e mudanças necessárias para o aprimoramento e avanços. É importante Estes apontamentos devem se constituir como pauta crucial nos debates tanto a nível local como nacional, para que as sugestões sejam tragam eco e levem a mudanças.

Percebe-se que a contribuição desse estudo está na reflexão e o conhecimento dos benefícios da residência para qualificação e aprimoramento profissional, bem como, as dificuldades vivenciadas nos cenários de atuação.

Para os serviços e trabalhadores de saúde, observa-se que a inserção dos programas de residência no âmbito dos serviços de saúde podem contribuir para a integralidade do cuidado, para aqueles que necessitam dos serviços oferecidos pelo SUS. Em relação às políticas e construção do conhecimento, foi demonstrado neste estudo que existem desafios para o aprimoramento do programa.

A limitação deste estudo diz respeito ao fato deste se reduzir a uma localização e a um grupo e programa apenas, o que torna-se necessário que seja feito estudos em outros programas de Residência Multiprofissional.

\section{REFERÊNCIAS}

1. Presidência da República (Brasil). Lei no․ 11.129, de 30 de junho de 2005. Institui o Programa Nacional de Inclusão de Jovens ProJovem; cria o Conselho Nacional da Juventude - CNJ e a Secretaria Nacional de Juventude; altera as Leis no 10.683 , de 28 de maio de 2003, e 10.429, de 24 de abril de 2002; e dá outras providências [Internet]. D.O.U., Brasília, DF, 01 jul 2005 [citado em 25 ago 2017]. Disponível em: http://www.planalto.gov.br/ccivil_03/_Ato2 004-2006/2005/Lei/L11129.htm

2. Ministério da Educação (Brasil). Comissão Nacional de Residência Multiprofissional em Saúde (Brasil). Resolução CNRMS n2), de 13 de abril de 2012. Dispõe sobre Diretrizes Gerais para os Programas de Residência Multiprofissional e em Profissional de Saúde [Internet]. D.O.U., Brasília, DF, 26 abr 2012 [citado em 25 ago 2017]. Disponível em: http://portal.mec.gov.br/index.php?option $=c$ om_docman\&view=download\&alias $=15448$ resol-cnrms-n2-13abril-2012\&Itemid $=30192$ 3. Ceccim RB. Educação permanente em saúde: descentralização e disseminação de capacidade pedagógica na saúde. Ciênc Saúde Colet. [Internet]. 2005 [citado em 25 ago 2017]; 10(4): 975-86. Disponível em: http://www.scielo.br/pdf/csc/v10n4/a20v1 0n4.pdf

DOI: http://dx.doi.org/10.1590/S1413-

81232005000400020

4. Ministério da Saúde (Br), Secretaria de Gestão do Trabalho e da Educação na Saúde, Departamento de Gestão da Educação na Saúde. Residência multiprofissional em saúde: experiências, avanços e desafios [Internet]. Brasília, DF: Ministério da Educação; 2006 [citado em 25 ago 2017]. Disponível em: http://bvsms.saude.gov.br/bvs/publicacoes/ residencia_multiprofissional.pdf 
5. Silva CT, Terra MG, Kruse MHL, Camponogara S, Xavier MS. Residência multiprofissional como espaço intercessor para a educação permamente. Texto \& Contexto Enferm. [Internet]. 2016 [citado em 25 ago 2017]; 25(1):1-9. Disponível em: http://www.scielo.br/pdf/tce/v25n1/01040707-tce-25-01-2760014.pdf. http://dx.doi.org/10.1590/01040707201600002760014

6. Peduzzi M, Norman IJ, Germani ACCG, Silva JAM, Souza GC. Interprofessional education: training for healthcare professionals for teamwork focusing on users. Rev Esc Enferm USP. [Internet]. 2013 [citado em 25 mar 2017]; 47(4):973-9. Disponível em: http://www.scielo.br/pdf/reeusp/v47n4/en _0080-6234-reeusp-47-4-0977.pdf

7. Miranda Neto MV, Leonello VM, Oliveira MAC. Multiprofessional residency in health: a document analysis of political pedagogical projects. Rev Bras Enferm. [Internet]. 2015 [citado em 25 ago 2017]; 68(4):586-93. Disponível

em:

http://www.scielo.br/pdf/reben/v68n4/en_ 0034-7167-reben-68-04-0586.pdf

http://dx.doi.org/10.1590/0034-

7167.2015680403i

8. Fontanella BJB, Ricas J, Turato ER. Amostragem por saturação em pesquisas qualitativas em saúde: contribuições teóricas. Cad Saúde Pública. 2008; 24(1):1727.

9. Minayo MCS. O desafio do conhecimento: pesquisa qualitativa em saúde. São Paulo: Hucitec; 2014.

10. Gomes PB. O significado e a motivação do trabalho para estagiários [Internet]. [Trabalho de conclusão de curso]. Brasília, DF: Escola Nacional de Administração Pública; 2014 [citado em 25 ago 2017]. 43p. Disponível em:

http://repositorio.enap.gov.br/bitstream/1/ 2660/1/0\%20significado\%20e\%20a\%20mo tiva\%C3\%A7\%C3\%A3o\%20do\%20trabalho \%20para\%20estagi\%C3\%A1rios.pdf

11. Giongo CR, Monteiro JK, Sobrosa GMR. Psicodinâmica do trabalho no Brasil: revisão sistemática da literatura [editorial]. Temas psicol. [Internet]. 2015 [citado em 25 ago 2017]; 23(4):803-14. Disponível em: http://pepsic.bvsalud.org/pdf/tp/v23n4/v2 3n4a01.pdf

DOI: http://dx.doi.org/10.9788/TP2015.4-01

12. Silva JC, Contim D, Ohl RIB, Chavaglia SRR, Amaral EMS. Percepção dos residentes sobre sua atuação no programa de residência multiprofissional. Acta Paul Enferm. [Internet] 2015 [citado em 25 ago 2017]; 28(2):132-8. Disponível em: http://www.scielo.br/pdf/ape/v28n2/19820194-ape-28-02-0132.pdf.

DOI:

http://dx.doi.org/10.1590/1982-

0194201500023

13. Loren RH. Papel do preceptor na residência multiprofissional: experiência da fisioterapia [Internet]. [Trabalho de conclusão de curso]. Porto Alegre: Universidade do Rio Grande do Sul - UFRGS; 2010 [citado em 25 ago 2017]. Disponível em: http://www.lume.ufrgs.br/bitstream/handle /10183/32960/000760548.pdf?sequence=1

14. Ribeiro KRB, Prado ML. A prática educativa dos preceptores nas residências em saúde: um estudo de reflexão. Rev Gaúch Enferm. [Internet]. 2013 [citado em 25 ago 2017]; 35(1):161-5. Disponível em: http://www.scielo.br/pdf/rgenf/v35n1/pt_1 983-1447-rgenf-35-01-00161.pdf. DOI: http://dx.doi.org/10.1590/1983-

1447.2014.01.43731

15. Botti SHO. Desenvolvendo as competências profissionais dos residentes. Rev. HUPE. [Internet]. 2012 [citado em 25 ago 2017]; 11(1):102-5. Disponível em: http://revista.hupe.uerj.br/detalhe_artigo.as p?id=317

16. Parente JRF, Dias MSA, Chagas MIO, Craveiro MVA. Trajetória da residência multiprofissional em saúde da família de Sobral. In: Ministério da Saúde (Br), Secretaria de Gestão do Trabalho e da Educação na Saúde, Departamento de Gestão da Educação na Saúde. Residência multiprofissional em saúde: experiências, avanços e desafios. Brasília, DF: Ministério da Saúde; 2006. p. 8196.

17. Mccaffrey RG, Hayes R, Stuart W, Cassel A, Farrell C, Miller-Reyes S, et al. An educational program to promote positive communication and collaboration between nurses and medical staff. J. Nurses Staff Dev. [Internet]. 
2011 [citado em 25 ago 2017]; 27(3):121-7. Disponível

em:

https://insights.ovid.com/crossref?an $=0012$ 4645-201105000-00004

DOI:

http://dx.doi.org/

10.1097/NND.0b013e318217b3ce

18. Aase I, Hansen BS, Aese K. Norwegian nursing and medical students' perception of interprofessional teamwork: a qualitative study. BMC Med Educ. [Internet]. 2014 [citado em 25 ago 2017]; 14(170):1-9. Disponível em: https://bmcmededuc.biomedcentral.com/tra ck/pdf/10.1186/1472-6920-14-170. DOI: https://doi.org/10.1186/1472-6920-14-170 19. Bunniss S, Kelly DR. The unknown becomes the known': collective learning and change in primary care teams. BMC Med Educ. [Internet]. 2008 [citado em 25 ago 2017]; 42(12):1185-94. Disponível em: https://onlinelibrary.wiley.com/doi/epdf/10 .1111/j.1365-2923.2008.03159.x. DOI: https://doi.org/10.1111/j.1365-

2923.2008.03159.x

20. Relatório da oficina: Desafios e perspectivas das residências em saúde coletiva: RMPS e residências multiprofissionais em saúde coletiva. In: IX Congresso Brasileiro de Saúde Coletiva [Internet]; 2009; Recife. Recife: ABRASCO; 2009 [citado em 20 ago 2015]. Disponível em: www.saudecoletiva2009.com.br/oficinas/RE LAT\%D3RI0\%200FICINA_Resid\%EAncias\% 20Multiprofissionais.pdf

21. Ministério da Saúde (Br), Secretaria de Gestão do Trabalho e da Educação na Saúde, Departamento de Gestão da Educação na Saúde. Relatório de atividades da comissão nacional de residência multiprofissional em saúde - CNRMS: exercício 2007/2009 [Internet]. Brasília, DF: Ministério da Saúde; 2009 [citado em 25 ago 2017]. Disponível em: http://www.sbfa.org.br/portal/pdf/Relatori o\%20Atividades\%20CNRMS\%202007\%202 009.pdf

22. Brunholi GN. Caminhando pelo fio da história: a residência multiprofissional em saúde nos espaços de construção da política de formação de trabalhadores para o SUS [Internet]. [Dissertação]. Vitória: Universidade Federal do Espírito Santo - UFE; 2013 [citado em 25 ago 2017]. Disponível em: http://repositorio.ufes.br/bitstream/10/128 4/1/Dissertacao\%20Gislene \%20do\%20Nasc imento\%20Brunholi.pdf

23. Mioto RCT, Alves FL, Caetano OS, Prá KRD. As residências multiprofissionais em saúde: a experiência da Universidade Federal de Santa Catarina. Serv Soc Saúde [Internet]. 2012 [citado em 25 ago 2017]; 2(14):185-208. Disponível em: https://periodicos.sbu.unicamp.br/ojs/index .php/sss/article/view/8635288. DOI: http://dx.doi.org/10.20396/sss.v11i2.86352 88

CONTRIBUIÇõES
Diane Coelho Pereira participou na
concepção, delineamento, análise e
interpretação dos dados e redação. Karina
Piccin Zanni atuou na concepção,
delineamento, análise e interpretação dos
dados, redação e revisão crítica. José
Henrique da Silva Cunha contribuiu na
análise, interpretação dos dados e redação.

\footnotetext{
Como citar este artigo (Vancouver)

Pereira DC, Zanni KP, Cunha JHS. Residência multiprofissional em saúde: percepções de residentes, preceptores e tutores. REFACS [Internet]. 2019 [citado em inserir dia, mês e ano de acesso]; 7(2):200-210. Disponível em: inserir link de acesso. DOI: inserir link do DOI.

\section{Como citar este artigo (ABNT)}

PEREIRA, D. C.; ZANNI, K. P.; CUNHA, J. H. S. Residência multiprofissional em saúde: percepções de residentes, preceptores e tutores. REFACS, Uberaba, MG, v. 7, n. 2, p. 200-210, 2019. DOI: inserir link do DOI. Disponível em: inserir link de acesso. Acesso em: inserir dia, mês e ano de acesso.

\section{Como citar este artigo (APA)}

Pereira, D.C., Zanni, K.P. \& Cunha, J.H.S. (2019). Residência multiprofissional em saúde: percepções de residentes, preceptores e tutores. REFACS, 7(2), 200-210. Recuperado em: inserir dia, mês e ano de acesso de inserir link de acesso. DOI: inserir link do DOI.
} 